\title{
RELATIONSHIP BETWEEN OCCUPATIONAL STRESS AND CARDIOVASCULAR DISEASES RISK FACTORS IN DRIVERS
}

HAMED BIGLARI ${ }^{1}$, MOHAMMAD HOSSEIN EBRAHIMI ${ }^{2}$, MARYAM SALEHI ${ }^{3}$, MOHSEN POURSADEGHIYAN ${ }^{4}$, IMAN AHMADNEZHAD ${ }^{5,6}$, and MILAD ABBASI ${ }^{7,8}$

${ }^{1}$ Gonabad University of Medical Sciences, Gonabad, Iran

Social Development and Health Promotion Research Center, School of Public Health,

Department of Environmental Health Engineering

${ }^{2}$ Shahroud University of Medical Sciences, Shahroud, Iran

Occupational and Environmental Health Research Center

${ }^{3}$ University of Tehran, Tehran, Iran

Department of Health Psychology, Faculty of Psychology and Education Sciences

${ }^{4}$ University of Social Welfare and Rehabilitation Sciences, Tehran, Iran

Pediatric Neurorehabilitation Research Center, Department of Ergonomics, School of Rehabilitation

${ }^{5}$ National Iranian Oil Company, Tehran, Iran

Iranian Petroleum Industry, Health Research Institute (IPI HRI)

${ }^{6}$ Tehran University of Medical Sciences, Tehran, Iran

School of Advanced Technologies in Medicine, Department of Addiction Study

${ }^{7}$ Kermanshah University of Medical Sciences, Kermanshah, Iran

Research Center for Environmental Determinants of Health (RCEDH)

${ }^{8}$ Tehran University of Medical Sciences, Tehran, Iran

School of Public Health, Department of Occupational Health Engineering

Funding: Tehran University of Medical Sciences, project No. 4957, entitled "The relationship between risk factors of cardiovascular disease and occupational stress among drivers." Grant manager: Prof. Hossein Kakoei (2012-2014), Mohsen Poursadeghiyan, Ph.D. (2014-2015).

Received: November 20, 2013. Accepted: July 8, 2015.

Corresponding author: M. Poursadeghiyan, University of Social Welfare and Rehabilitation Sciences, Pediatric Neurorehabilitation Research Center, Department of Ergonomics, School of Rehabilitation, Kodakyar Ave., Daneshjo Blvd., Evin, 1985713834 Tehran, Iran (e-mail: mo.poursadeghiyan@uswr.ac.ir). 


\begin{abstract}
Objectives: Of all work stressors, occupational stress is the leading cause of many disorders among workers. Drivers are classified as a high risk group for work related stress. This study set out to determine the relationship between risk factors of cardiovascular diseases and occupational stress among drivers. Material and Methods: Two hundred and twenty two Ilam's intercity drivers were selected for the study. For measuring work stress, the Osipow work stress questionnaire was used. After a 10-h fasting period, systolic and diastolic blood pressure was recorded. Intravenous blood samples were taken to determine cholesterol, triglyceride and blood glucose levels. The independent samples t-test and Pearson's correlation test were used to assess the relationship between variables and occupational stress. Results: Seventy-one percent of the intercity drivers suffered from average to acute stress, and 3.1\% of them suffered from acute stress. There was no significant relationship between occupational stress and diastolic blood pressure $(p=0.254)$ among the drivers. Nevertheless, the Pearson's correlation test demonstrated a strong relationship between work stress and blood glucose $(\mathrm{p}<0.01)$, while no strong correlation was found for blood triglycerides and cholesterol levels. Conclusions: Based on the results, high rates of occupational stress were observed in the Ilam's intercity drivers. Occupational stress may have effect on blood glucose levels but the results did not suggest a considerable relationship between risk factors of cardiovascular diseases and occupational stress among intercity drivers. Int J Occup Med Environ Health 2016;29(6):895-901
\end{abstract}

Key words:

Risk factors, Cardiovascular diseases, Occupational stress, Osipow, Drivers, Cardiovascular risk factors

\section{INTRODUCTION}

Among new global health priorities, cardiovascular diseases, as a major public health concern, have become a central issue for public health experts. Cardiovascular diseases are the main cause of more than a half of all mortalities in the developed countries [1]. The incidence of cardiovascular diseases is greatly associated with the presence of some risk factors such as smoking, lack of physical activity, hypertension, overweight, hyperinsulinemia and hypercholesterolemia [2-4].

Of numerous workplace stressors such as physical, ergonomic, biological and chemical stressors, occupational stress is the leading cause of many disorders among workers [5-8]. Occupational stress is the physical and psychological strain, which happens when there is inconsistency between the objective or cognitive demands of the work environment and the individual compatibilities [9].In 1992, The United Nations declared occupational stress as a problem of the 20th century. A few years later, World Health Organization (WHO) addressed it as a major global health problem. International Labour Organization (ILO) estimated the cost of occupational stress to the society and it was about $1-3.5 \%$ of the gross domestic product (GDP). Recently, literature has revealed that $30 \%$ of workers in the developed countries suffer from occupational stress and this condition is even worse in the under developed countries [5]. Some health outcomes related to occupational stress include: prevalence of musculoskeletal complaints, sleep disturbance, tension, fatigue and problems of the stomach and intestines [10]. Also, occupational stress is associated with other types of chronic health problems such as disorders affecting the heart and blood vessels $[10,11]$. In the past years, various studies demonstrated the role of stress in the development of cardiovascular diseases [12,13]. It is considered as one of the most important risk factors for these diseases, and there are certain relationships between occupational stress, hypertension and heart diseases $[11,14,15]$. Also, most recent reviews confirm the relationship between psychosocial stress and cardiovascular diseases [16]. Recently, research has investigated the relationships between occupational stress and changes in blood glucose and cholesterol levels $[5,17]$. Even though drivers may have lower frequency of sickness than other occupational categories, this occupational category has been classified as a high risk group for workrelated stress [10]. The aim of this study was to determine the relationship between risk factors of cardiovascular diseases and occupational stress among the drivers who were assumed to have been affected by stress because of their working environment. Estimation of the distribution 
of various disorders and determination of their causes can help reduce the rate of such disorders and plan preventive programs for the future.

\section{MATERIAL AND METHODS}

This cross-sectional study was conducted in 2010, in Ilam one of Iran's provinces. Of 250 intercity drivers, 224 subjects were selected for this study. Other drivers were excluded because some of their medical records were unavailable. The sample size of the study was adopted with a confidence level of $95 \%$ and error level of $1 \%$. All the participants had at least 3 years of work experience. A questionnaire was used to gather information on demographic characteristics and work stress. The questionnaires were filled in via conducting interviews with the respondents.

In order to measure work stress, the Osipow work stress questionnaire (revised in 1998) was used [5]. The questionnaire contains 60 questions divided in to 6 groups (10 questions in each group). The answers were ranked based on a 5-point Likert's scale (1-5). Total score from all the questions was calculated and interpreted based on the manual of the questionnaire - scores ranging 60-119 were referred to as mild stress, 120-179 as average stress, 180-239 as average to acute stress, and 240-300 as acute stress. Based on the scores of the Osipow questionnaire, the subjects were divided into 2 groups - group 1: mild and mild-average stress, and group 2: average-acute and acute stress. Validity and reliability of the questionnaire have been confirmed in other studies [18].

All the participants were informed about the study and were asked to refer to the health facilities after a 10-h fasting period. Time of the last meal before systolic and diastolic blood pressure determination was recorded. The test was performed by an attending physician in a sitting position and using a standard mercury manometer after a short rest time. The result was the average of 2 consecutive tests. The study was performed based on dossiers and personal memoirs.
Following the drivers' referrals to medical clinics where they work, information concerning their state of health was obtained. The participants with diabetic records, heart diseases and those using blood pressure and cholesterol medications were excluded from the study. Intravenous blood samples were taken to check cholesterol, triglyceride and blood glucose levels. Moreover, height and weight of the participants were measured. Data were analyzed in SPSS (Statistical Package for Social Sciences, version 16). The independent samples t-test and Pearson's correlation test were used to assess the relationship between the variables and stress levels. The result was considered significant if the $p$ value was at 0.05 level $(p=0.05)$.

\section{Ethical considerations}

Ethical points, including: conduct and reporting of the research, contributions, authorship as well as declaration of Helsinki on ethical principles for medical research involving human subjects were considered.

\section{RESULTS}

The average age of the drivers participating in this study was $38.9 \pm 6.13$ years, with age range of $20-63$ years. According to the results, $74.6 \%, 14.3 \%$, and $4.5 \%$ of drivers had a diploma, an associate degree and a higher education level, respectively. About $27.2 \%$ of the subjects had work duration of 20 years or more. In general, drivers should work $8 \mathrm{~h} /$ day and then rest for $16 \mathrm{~h}$; however, the intercity drivers of Ilam, on average worked 13.62 $\pm 3.64 \mathrm{~h} /$ day. About 26.33\% ( $\mathrm{N}=59)$ of the participants had a smoking habit, and the average height, weight, and body mass index (BMI) were: $172.36 \pm 6.33 \mathrm{~cm}, 75.92 \pm 11.57 \mathrm{~kg}$, $25.4 \mathrm{~kg} / \mathrm{m}^{2}$ (an acceptable BMI), respectively.

Table 1 illustrates some of the main demographic characteristics of the study participants.

Blood glucose level of 10 subjects (7.1\%) was higher than $115 \mathrm{mg} / \mathrm{dl}$; cholesterol of 39 participants (28.3\%) was higher than $200 \mathrm{mg} / \mathrm{dl}$; triglyceride level 
Table 1. Demographic characteristics of the drivers, Iran, 2010

\begin{tabular}{lrr}
\hline \multirow{2}{*}{ Characteristics } & \multicolumn{2}{c}{ Respondents } \\
\cline { 2 - 3 } Age & $\mathrm{n}$ & $\%$ \\
20-30 years & 32 & 14.2 \\
31-41 years & 123 & 54.9 \\
42-52 years & 47 & 21.0 \\
53-63 years & 22 & 9.8 \\
Work experience & & \\
1-10 years & 113 & 50.4 \\
11-20 years & 50 & 22.3 \\
$>$ 20 years & 61 & 27.2 \\
Level of education & & \\
high school & 15 & 6.6 \\
diploma & 167 & 74.6 \\
associate degree & 32 & 14.3 \\
bachelor & 10 & 4.5 \\
Gender & & \\
male & 224 & 100.0 \\
female & 0 & 0.0 \\
\hline
\end{tabular}

of 21 participants $(15.2 \%)$ was above $240 \mathrm{mg} / \mathrm{dl}$; systolic blood pressure of 11 drivers (4.9\%) and diastolic blood pressure of $17(7.6 \%)$ drivers were higher than $140 \mathrm{~mm} \mathrm{Hg}$ and $90 \mathrm{~mm} \mathrm{Hg}$, respectively.
Table 2. Occupational stress in drivers, Iran, 2010

\begin{tabular}{lrr}
\hline \multirow{2}{*}{\multicolumn{1}{c}{ Stress intensity }} & \multicolumn{2}{c}{ Respondents } \\
\cline { 2 - 3 } & $\mathrm{n}$ & \multicolumn{1}{c}{0} \\
\hline Mild stress & 0 & 0.0 \\
Average stress & 57 & 25.4 \\
Average to acute stress & 160 & 71.4 \\
Acute stress & 7 & 3.1 \\
\hline
\end{tabular}

Results of the Osipow work stress questionnaire showed that $25.4 \%$ of the participants suffered from average stress, $71.4 \%$ suffered from average to acute stress, and 3.1\% suffered from acute stress (Table 2). Therefore, $25.4 \%$ of them were placed in group 1 and $74.5 \%$ in group 2.

The mean of cardiovascular risk factors in both groups (suffering from stress) can be seen in Table 3.

Analysis of the correlation between the risk factors and work stress showed that except for blood glucose levels $(\mathrm{p}<0.01)$, there was no significant relationship between cardiovascular diseases risk factors, such as: blood triglycerides levels $(p=0.231)$, blood cholesterol levels $(p=0.531)$ and diastolic blood pressure $(p=0.254)$ and work stress (Table 4$)$.

Furthermore, the Pearson's correlation test demonstrated a strong relationship between work stress and blood glucose, while no strong correlation was found for other risk factors of cardiovascular diseases.

Table 3. Cardiovascular risk factors in both groups of the drivers affected by stress, Iran, 2010

\begin{tabular}{|c|c|c|}
\hline \multirow[t]{2}{*}{ Risk factor } & \multicolumn{2}{|c|}{$\begin{array}{l}\text { Group } \\
(\mathrm{M} \pm \mathrm{SD})\end{array}$} \\
\hline & $1^{*}$ & $2 * *$ \\
\hline Smoking [filter/day] & $2.31 \pm 13.5$ & $2.72 \pm 9.7$ \\
\hline Blood glucose level [mg/dl] & $99.5 \pm 37.2$ & $82.4 \pm 11.7$ \\
\hline Blood triglycerides level [mg/dl] & $177.6 \pm 106.1$ & $160.4 \pm 88.7$ \\
\hline Blood cholesterol level [mg/dl] & $186.2 \pm 37.4$ & $182.2 \pm 42.9$ \\
\hline Diastolic blood pressure [mm Hg] & $78.5 \pm 13.3$ & $76.5 \pm 10.7$ \\
\hline Systolic blood pressure [mm Hg] & $119.5 \pm 17.7$ & $116.9 \pm 12.6$ \\
\hline
\end{tabular}

* Group suffered from mild and average stress.

** Group suffered from average to acute and acute stress.

M - mean; SD - standard deviation. 
Table 4. Relationship between work stress and the risk factors of cardiovascular diseases in the drivers, Iran, 2010

\begin{tabular}{lrc}
\hline \multicolumn{1}{c}{ Parameter } & \multicolumn{1}{c}{$\mathrm{p}$} & $\mathrm{r}$ \\
\hline Smoking & 0.461 & 0.506 \\
Blood glucose level & $<0.010$ & 0.842 \\
Blood triglycerides level & 0.231 & 0.080 \\
Blood cholesterol level & 0.531 & 0.042 \\
Diastolic blood pressure & 0.254 & 0.069 \\
Systolic blood pressure & 0.229 & 0.078 \\
\hline
\end{tabular}

r - Pearson's correlation coefficient.

\section{DISCUSSION}

The study was conducted in order to determine work stress and its relationship with cardiovascular risk factors. High rates of occupational stress were observed in the study subjects. In our previous study on drivers, $68 \%$ of them were placed in a medium-to-high stress group [19]. It has been shown that driving can generate stress. Although in the present investigation, $74.5 \%$ of the participants were reported to have had average and acute stress, no significant differences were found between the risk factors of cardiovascular diseases and occupational stress.

Possible explanations for this might include: a short period of this study, disregarding the effects of stress on cardiovascular diseases in a long period of time and the young average age of the participants. Pelfrene et al. (2002) have reported no significant relationship between risk factors of cardiovascular diseases and work stress [20]. The relationship between smoking and occupational stress was positive but not significant. This finding is in agreement with Kouvonen's (2005) findings [21]. Belkic et al. (2004) have shown a significant relationship between risks factors of cardiovascular diseases and work stress [22]; but the results by Demiral et al. (2006) have not confirmed those results [17]. Another important finding was that there was a significant relationship and strong correlation between work stress and blood glucose. Golmohammadi et al. (2006) have studied diabetic patients and found a significant relationship between occupational stress and diabetes [23]. However, their results cannot be compared directly with ours because of different tools used in the 2 studies.

There was no significant relationship between occupational stress and changes in lipid profile of blood and the positive correlation between them was too weak. The findings of the current study are consistent with those of Su (2001) and Netterstrøm et al. (1991), who have found no significant relationship between stress and blood cholesterol [24,25]. Furthermore, this finding corroborates the ideas of Kobayashi (2005) and Yadegarfar et al. (2010), who have suggested that there was no significant relationship between occupational stress and blood triglycerides [26,27]. Although, these results differ from Kobayashi's (2005) study, their study has found a significant difference and positive relationship between blood cholesterol and stress [27]. This inconsistency may be due to the methodology and the study groups differences.

High rate of diastolic blood pressure was reported among the participants, but no significant differences were found between diastolic blood pressure and occupational stress. Franke et al. (2010) have found no relationship between occupational stress and risk factors of cardiovascular diseases, although high stress rate was observed among their study participants [28].

The results showed that the average work performed by drivers lasted $13.62 \pm 3.64 \mathrm{~h} /$ day and this may have led to excessive occupational stress. Surveys such as that conducted by Uehata (1991) have shown that occupational stress was related to long working hours [29].

Since the present study was a cross-sectional one, its results are less reliable in comparison with the studies conducted during longer periods of time. Therefore, our results cannot be used as a basis to claim that there is no relationship between occupational stress and risk factors of cardiovascular diseases. Long term studies are required to determine the relationship between variables and confirm validity of the results. Another limitation of the presented 
study was weariness of the participants during the interview. To avoid any disturbance, the interview sessions were held at the end of their work shifts. Some other limitations of the study were: poor cooperative attitude among staff due to time shortage and lack of similar surveys in Iran. It is essential to conduct further studies so as to determine effects of work stress on risk factors of cardiovascular diseases (such as smoking).

\section{CONCLUSIONS}

Based on the results, high rates of occupational stress were observed in the Ilam's intercity drivers. Occupational stress may have effect on blood glucose levels but the results did not suggest a considerable relationship between the risk factors of cardiovascular diseases and occupational stress among the studied intercity drivers.

\section{ACKNOWLEDGMENTS}

The authors wish to thank all the supervisors and drivers for their assistance in this study and are very grateful for their cooperation. The authors also appreciate great help of Professor Hossein Kakoei. May he rest in peace.

\section{REFERENCES}

1. American Heart Association. Heart disease and stroke statistics - 2005 update [Internet]. Dallas: The Association; 2005 [cited 2014 October 10]. Available from: https:// my.clevelandclinic.org/ccf/media/files/heart/1105390918119H DSStats2005Update.pdf.

2. Ramji R. Assessing the relationship between occupational stress and periodontitis in industrial workers [dissertation]. Umeä: Umeä University; 2010.

3. Pyörälä M, Miettinen H, Halonen P, Laakso M, Pyörälä K. Insulin resistance syndrome predicts the risk of coronary heart disease and stroke in healthy middle-aged men the 22-year follow-up results of the Helsinki Policemen Study. Arterioscler Thromb Vasc Biol. 2000;20(2):538-44, http://dx.doi. org/10.1161/01.ATV.20.2.538.
4. Williams MA, Petratis MM, Baechle TR, Ryschon KL, Campain JJ, Sketch MH. Frequency of physical activity, exercise capacity, and atherosclerotic heart disease risk factors in male police officers. J Occup Environ Med. 1987;29(7): 596-600.

5. Aminian O, Farjami A, Pouryaghoob G, Sadeghniiat Haghighi K. [The evaluation of effect of job stress on the risk factors of the cardiovascular diseases among the drivers in Tehran in 86]. Tkj. 2011;2(1):26-33. Persian.

6. Rahmani A, Mahmodkhani S, Moslemi M, Gharagozlou F, Ahmadnezhad I, Karchani M, et al. Investigation of occupational stress and its relationship with the demographic characteristics of workers in Ilam. Iran Electron Physician. 2013;5(1):611-5.

7. Karchani M, Barkhordari A, Pornajaf A, Raei M, Asaadi Z, Khobi J, et al. Job stress and related factors in nurses in Ilam. Iran Electron Physician. 2012;4(1):465-9.

8. Farhadi R, Omidi L, Balabandi S, Barzegar S, Abbasi AM, Poornajaf $\mathrm{AH}$, et al. Investigation of musculoskeletal disorders and its relevant factors using quick exposure check (QEC) method among seymareh hydropower plant workers. JRH. 2014;4(2):714-20.

9. Wang S, Chang D. Occupational stress and coronary artery disease. In: Chaikovsky I, Sydorova NN, editors. Coronary artery diseases. Rijeka: InTech; 2012, http://dx.doi.org/ $10.5772 / 30704$.

10. Kompier M. Bus drivers: Occupational stress and stress prevention. Geneva: International Labour Office; 1996. p. 5-8.

11. Mariammal T, Jaisheeba AA, Sornaraj R. Work influenced occupational stress and cardiovascular risk among teachers and office workers. Chem Pharm Res. 2012;4(3):1807-11.

12. Kaplan JR, Chen H, Manuck SB. The relationship between social status and atherosclerosis in male and female monkeys as revealed by meta-analysis. Am J Primatol. 2009;71(9):732-41, http://dx.doi.org/10.1002/ajp.20707.

13. Cohen S, Janicki-Deverts D, Miller GE. Psychological stress and disease. JAMA. 2007;298(14):1685-7, http://dx.doi.org/ 10.1001/jama.298.14.1685. 
14. Pickering T, Devereux R, James G, Gerin W, Landsbergis $\mathrm{P}$, Schnall $\mathrm{P}$, et al. Environmental influences on blood pressure and the role of job strain. J Hypertens Suppl. 1996;14(5):S179-85.

15. Schnall PL, Schwartz JE, Landsbergis PA, Warren K, Pickering TG. A longitudinal study of job strain and ambulatory blood pressure: Results from a three-year follow-up. Psychosom Med. 1998;60(6):697-706, http:/dx.doi.org/ 10.1097/00006842-199811000-00007.

16. Hemingway H, Marmot M. Psychosocial factors in the aetiology and prognosis of coronary heart disease: Systematic review of prospective cohort studies. BMJ. 1999;318 (7196):1460-7, http://dx.doi.org/10.1136/bmj.318.7196.1460.

17. Demiral Y, Soysal A, Can Bilgin A, Kiliç B, Unal B, Uçku R, et al. The association of job strain with coronary heart disease and metabolic syndrome in municipal workers in Turkey. J Occup Health. 2006;48(5):332-8, http://dx.doi.org/ 10.1539/joh.48.332.

18. Malek M, Mohammadi S, Attarchi M. [Occupational stress and influencing factors, in medical residents of one of the educational hospitals of Tehran University of Medical Sciences]. RJMS. 2011;18(87):24-35. Persian.

19. Rahmani A, Farjami A, Mahmodkhani S, Gharagozlo F, Ahmadnezhad I, Karchani M, et al. Determination of job stresses and their consequences in drivers in Ilam. Electron Physician. 2013;5(1):594-8.

20. Pelfrene E, De Backer G, Mak R, de Smet P, Kornitzer M. Job stress and cardiovascular risk factors. Arch Public Health. 2002;60:245-68.

21. Kouvonen A, Kivimaki M, Virtanen M, Pentti J, Vahtera J. Work stress, smoking status, and smoking intensity: An observational study of 46190 employees. J Epidemiol Community Health. 2005;59(1):63-9, http://dx.doi.org/10.1136/ jech.2004.019752.
22. Belkic K, Landsbergis PA, Schnall PL, Baker D. Is job strain a major source of cardiovascular disease risk? Scand J Work Environ Health. 2004:85-128, http://dx.doi.org/10.5271/ sjweh.769.

23. Golmohammadi R, Abdulrahman B. Relationship between occupational stress and non-insulin-dependent diabetes in different occupation in Hamadan (West of Iran). J Med Sci. 2006;6(2):241-4, http://dx.doi.org/10.3923/jms.2006.241.244.

24. Su C-T. Association between job strain status and cardiovascular risk in a population of Taiwanese white-collar workers. Circ J. 2001;65(6):509-13, http://dx.doi.org/10.1253/ jcj.65.509.

25. Netterstrøm B, Kristensen TS, Damsgaard MT, Olsen O, Sjøl A. Job strain and cardiovascular risk factors: A cross sectional study of employed Danish men and women. $\mathrm{Br}$ J Ind Med. 1991;48(10):684-9, http://dx.doi.org/10.1136/ oem.48.10.684.

26. Kobayashi Y, Hirose T, Tada Y, Tsutsumi A, Kawakami N. Relationship between two job stress models and coronary risk factors among Japanese part-time female employees of a retail company. J Occup Health. 2005;47(3):201-10, http:// dx.doi.org/10.1539/joh.47.201.

27. Yadegarfar G, Alinia T, Gharaaghaji Asl R, Allahyari T, Sheikhbagloo R. [Assessing the relationship between occupational stress and risk factors of cardiovascular in the Urmia petrochemical company employees]. J Isfahan Med Sch. 2010;28(112):645-60. Persian.

28. Franke WD, Kohut ML, Russell DW, Yoo HL, Ekkekakis P, Ramey SP. Is job-related stress the link between cardiovascular disease and the law enforcement profession? J Occup Environ Med. 2010;52(5):561-5.

29. Uehata T. Long working hours and occupational stressrelated cardiovascular attacks among middle-aged workers in Japan. J Hum Ergol. 1991;20(2):147-53.

This work is available in Open Access model and licensed under a Creative Commons Attribution-NonCommercial 3.0 Poland License - http://creativecommons.org/ licenses/by-nc/3.0/pl/deed.en. 